\title{
ESPAÇOS NÃO-FORMAIS NA EDUCAÇÃO
}

\author{
Adriana Lúcia de Arruda ${ }^{1}$ \\ Claudiani Aparecida de assunção Almeida ${ }^{2}$ \\ Ivalleica Ferreira da Costa ${ }^{3}$ \\ Letícia Adrielle Malaquias de Oliveira Almeida ${ }^{4}$ \\ Ua-Naia Aparecida Luz ${ }^{5}$ \\ Vania Valesca Castilho da Silva Santos ${ }^{6}$
}

RESUMO: O foco deste artigo está relacionado ao pedagogo e sua atuação nos espaços de educação não formal e como coadjuvante das disciplinas na escola. Mais especificamente, atividades extraclasse. Nesse objetivo, esse profissional se apresenta como um orientador e orientador do trabalho, além das paredes físicas de uma escola. A educação não formal, suas práticas e experiências fora da escola foram conceituadas, bem como a promoção do desenvolvimento e socialização dos alunos nesses locais. Este profissional possui especificidades e utiliza diferentes metodologias e em diferentes ambientes. O tema foi escolhido por ser um tema atual e relevante para a formação desse profissional. Este é também o resultado da sua formação e da sua prática pedagógica exercida nestes locais com diferentes contextos. As atividades nesta área da Educação recebem denominações diferentes e podem variar de acordo com a sua natureza, mas têm em comum a sua execução em ambiente não escolar. Ensinar não é uma imposição, pois o ato de ensinar e aprender implica escolha, decisão, responsabilidade. Por fim, existe uma essência no ensino e aprendizagem que esses profissionais devem compreender por meio de sua aprendizagem profissional.

Palavras-chave: Educação não-formal. Desenvolvimento. Ensinar.

ABSTRACT: The focus of this study is the studies related to the pedagogue and its performance in non-formal education spaces and as an aid to subjects at school. More specifically, extra-class activities. In this objective, this professional is presented as an advisor and guide of the work, in addition to the physical walls of a school. Non-formal education, its practices and out-of-school experiences were conceptualized, as well as the promotion of development and socialization of students in these places. This professional has specificities and uses different methodologies and in different environments. The

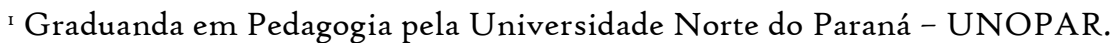

2 Graduada em Pedagogia pelas Faculdades Integradas de Várzea Grande - FIAVEC, Especialista em Alfabetização e Educação Infantil pelas Faculdades Integradas de Várzea Grande - FIAVEC.

3 Graduada em Pedagogia pela Faculdade Educacional da Lapa - FAEL, Especialista em Alfabetização pela Universidade do Estado de Mato Grosso - UNEMAT

4 Graduada em Pedagogia pela Anhanguera, Especialista em Educação Infantil e Alfabetização pela Faculdade Impactos Brasil - FACIB.

5 Graduada em Administração pelo Centro Universitário UNIVAG, Especialista em Fundamentos daEducação, Didática e Docência do Ensino Superior pelo Centro Univeristário - UNIVAG, Especialista em Psciopedagogia pelo IESMIG - Instituto de Ensino Superior de Minas Gerais.

${ }^{6}$ Graduada em Pedagogia pela Faculdade INVEST de Ciências e Tecnologias, Especialista em Educação Infantil pelo IESMIG - Instituto de Ensino Superior de Minas Gerais.
} 
theme was chosen because it is a current and relevant theme for the training of this professional. This is also the result of their training and their pedagogical practice used in these places with different contexts. Activities in this area of Education receive different names and can vary according to their nature, but they have in common their execution in a non-school environment. Teaching is not an imposition, as the act of teaching and learning implies choice, decision, responsibility. Finally, there is an essence in teaching and learning that these professionals must understand through their professional learning.

Keywords: Non-formal education. Development. To teach.

\section{INTRODUÇÃO}

O ensino aos alunos que participam da primeira fase de aprendizagem em suas vidas, pode se processar em diferentes contextos educacionais e espaciais. Vê-se este aspecto, no trabalho de Oliveira e Gastal (2009) e ainda, para cada contexto, diferentes definições e caracterizações que são consideradas.

Neste artigo, referiremos os ambientes extra-escolares, aqueles inseridos na educação formal ou educação escolarizada, considerando aqui uma relação com o espaço onde transcorre o processo educacional, que é comumente empregado na diferenciação dos conceitos de educação formal, não-formal e informal.

Existem, entretanto outros aspectos determinantes para esta nomenclatura que também são utilizadas em educação, tais como a questão do meio onde acontece, o processo educativo e a relação entre os sujeitos envolvidos no processo.

Em termos gerais, muitos recursos são levados em conta no caso das atividades da educação não-formal, aqui consideradas as atividades extra-classes, como: a intenção didática, a metodologia e suas técnicas específicas, a própria avaliação, que logicamente depende, do que for ou foi executado. Autores dizem a respeito deste tipo de construção do conhecimento que: em crianças de diferentes grupos sociais, isso depende e ocorre, por meio de estratégias diferentes e que atendem inclusive as necessidades da sobrevivência dos agrupamentos, socioculturais distintos (FELTRAN e FELTRAN FILHO, 2007).

Considera-se neste artigo também que não existe um consenso, na diferenciação dos conceitos de educação formal, não-formal e informal e diferentes autores empregam uma mesma terminologia para exemplificar situações distintas Rocha e Fuscaldo, (2010, p. I05), então nossa hipótese se apoia nos conceitos e na necessidade que estes profissionais, 
procurem por atividades extra classes, executando-as e sabendo então como se posicionar, como um profissional atuante, em sua profissão. Usar ou não, atividades extra-classes?

\section{DESENVOLVIMENTO}

\section{I AS ATIVIDADES PRÁTICAS OU NÃO-FORMAIS ESCOLARES}

Esse tipo de atividade, vinculada a uma disciplina e/ou projeto ou intenção pedagógica do orientador de classe, recebe diferentes denominações que podem variar de acordo com a sua natureza, mas que têm em comum a sua execução em um ambiente (espaço), não escolar.

Um exemplo do conceito e para demonstração, consta no quadro abaixo, conforme Rocha e Fuscaldo (2010) apud Jacobucci, (2008, p. 57).

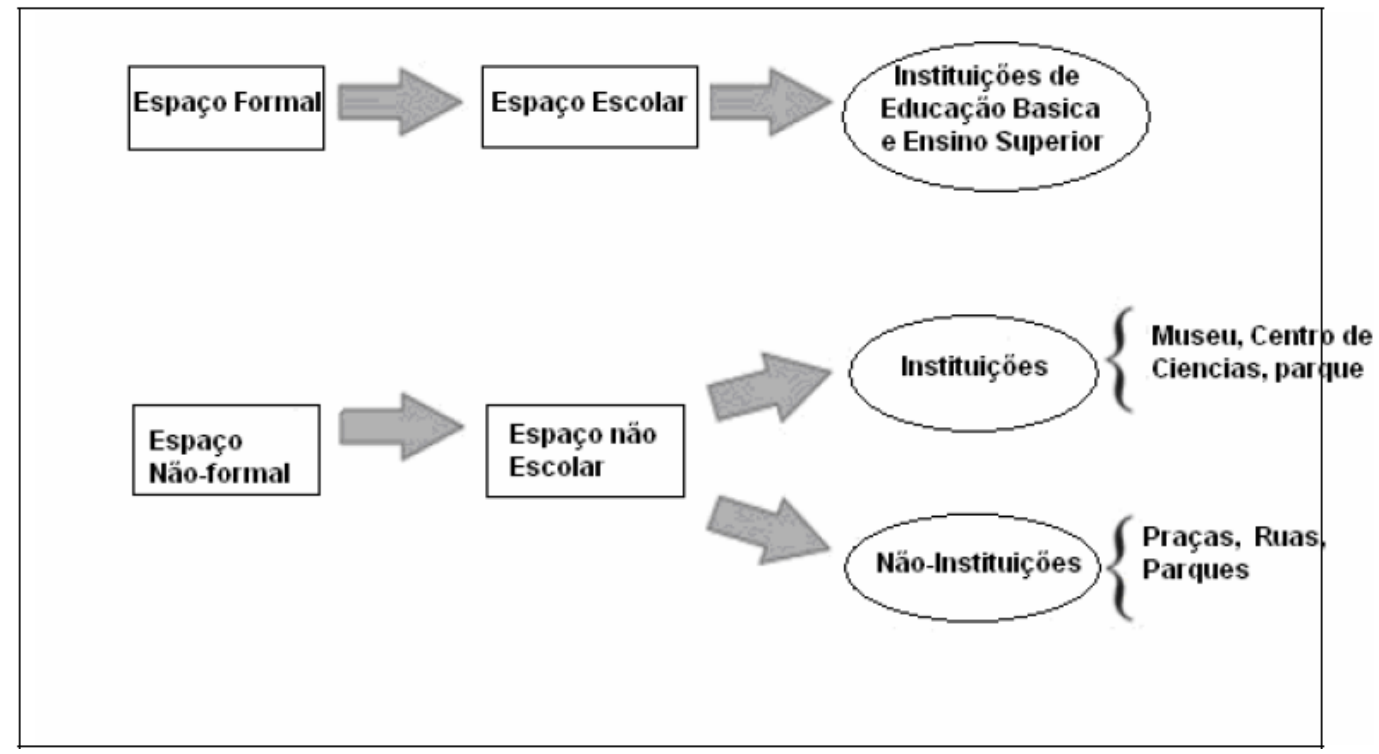

Fonte: Sugestões de definições para espaço formal e não-formal de educação.

Retirado de Rocha e Fuscaldo (2010) apud Jacobucci, (2008, p. 57).

Alguns exemplos podem ser citados como aulas práticas, aulas de campo, saídas em visitas a museus, a laboratórios de Universidades (ex: laboratórios de Anatomia quando a intenção é conhecer o corpo humano, etc).

As atividades são de usos diferenciados e até interdisciplinares, exemplo da educação ambiental onde num mesmo espaço, consegue-se explorar os conhecimentos de Ciências e Matemática e/ou outras disciplinas escolares. 
Em outra abordagem, se sabe que as salas de aulas de uma escola são consideradas como ambientes convencionais de ensino, o que significa dizer que os espaços "fora de sala de aula" podem ser classificados, de acordo como propõem Xavier e Fernandes (2008), como espaços não-convencionais de ensino.

Então cabe aqui a definição de espaço, como um conjunto indissociável de sistemas de objetos naturais ou fabricados e de sistemas de ações, deliberadas ou não. Da mesma forma, pode ser estendida para contextos mais amplos, que vão além das paredes da sala de aula e das fronteiras das escolas (XAVIER e FERNANDES, 2008).

De acordo com Jacobucci (2008, p. 56) o espaço formal é o espaço escolar, trata-se das Instituições Escolares da Educação Básica e do Ensino Superior, através da lei 9394/96 de Diretrizes e Bases da Educação Nacional.

Acerca das práticas pedagógicas em espaços não escolares, cita-se Veiga (1992) onde o mesmo diz que a mesma se comporta: "como uma prática social orientada por objetivos, finalidades e conhecimentos, e inserida no contexto da própria prática”.

Conforme Rego et al. (20II, p. 88) nos espaços não formais são desenvolvidas ações que objetivam promover a articulação entre a escola e os espaços de aprendizagem de seu entorno. Através dos seus projetos educativos interdisciplinares desenvolvidos em sala de aula, articulados como os conteúdos escolares, destaca-se a utilização da leitura de mapas e roteiros, desenvolvimento de temáticas tais como meio ambiente, multiculturalismo, ética, preservação do patrimônio e artes.

Também Freire (1996, p. 47) sobre a educação, tema de muitos trabalhos deste autor, traz o reforço para esta pesquisa, onde diz: "ensinar não é transferir conhecimento, mas criar as possibilidades para a sua própria produção ou sua construção”.

Conforme Heidegger (1952) apud Paviani (2003, p. 15) é preciso [...] "deixar aprender", pois para este autor entre o ensinar e aprender não há uma lógica, nem é algo natural, afirma que ensinar não é impor isso ou aquilo, pois o ato de aprender, no sentido mais elevado, sugere escolha, decisão, responsabilidade. Considera ainda que a essência do aprender envolve a compreensão.

O trabalho executado nestes locais de intenção didática deve trazer para o professor, o objetivo em termos de atividade em que o mesmo vai trabalhar e que este, esteja o mais próximo possível, da vida cotidiana de seus alunos. 
Para Oliveira e Gastal (2009) apud Rangel (2005, p. 29) é importante que o ensinoaprendizagem comece pelo conhecimento que seja mais próximo possível da realidade do aluno, com base nos fatos imediatos para os mais remotos, do concreto para o abstrato, do conhecido para o desconhecido.

Para o aluno, nestes ambientes de educação não-formal e também para a própria educação. Gohn (2010, p. 29-30) diz que a educação não-formal capacita os indivíduos a se tornarem cidadãos, sendo que seus objetivos não são dados a priori, se constroem no processo interativo, gerando um processo educativo, onde o educar surge como resultado do processo voltado para os interesses e as necessidades que dele participa.

A construção de relações sociais com base em princípios de igualdade e justiça social, quando presentes num dado grupo social, fortalece o exercício da cidadania. A transmissão de informação e formação política e sociocultural é uma meta na educação não formal, preparando os cidadãos, educando-os para a civilidade, em oposição à barbárie, ao egoísmo, individualismo.

O que se nota é que esses espaços possibilitam para as escolas e seus alunos e educadores, uma gama de atividades diversas, em que a socialização é muito presente, o aumento do conhecimento é agregado e a utilização do mesmo se torna real e possível, além da aprendizagem, passar a ser totalmente significativa.

\subsection{A ATUAÇÃO DO PEDAGOGO NOS ESPAÇOS NÃO-FORMAIS DE EDUCAÇÃO}

A escola é um espaço de educação formal, onde os professores e alunos se comunicam e se educam. Ela é destinada ao processo de ensino-aprendizagem, tanto quanto nos espaços não-formais aqui tratados como os espaços extra-classes, ou seja, fora da escola.

Nesse propósito surgem as inquietações próprias do futuro profissional pedagogo e que se mostra, em termos de perfil profissional: "de que forma as práticas pedagógicas de pedagogos que atuam em espaços não escolares, têm se constituído dentro dos processos de formação, deste profissional".

Assim como a escola, o profissional pedagogo deve pensar que o espaço da educação não-formal também se constitui em ambiente de disputa pela hegemonia, podendo 
converter-se em ambiente de fecunda discussão e diálogo mediatizado, pela realidade (GERMANO, 20II, p. 340).

Para Gohn (2008, p. 134) diz que a educação não-formal é destinada para o ser humano como um todo, não substituindo ou competindo com a educação formal ou escolar, mas ajuda na sua complementação, através de programações específicas, articulando escola e comunidade educativa localizadas no território do entorno escolar.

A educação não-formal tem alguns de seus objetivos próximos da educação formal, como a formação de um cidadão pleno, mas ela tem também a possibilidade de desenvolver alguns objetivos que lhes são específicos, via à forma e espaço onde se desenvolvem suas práticas, a exemplo de um fator motivacional, ou a participação em uma luta social, contra as discriminações, por exemplo: a favor das diferenças culturais, em termos de gênero, em termos de apresentação da História da região e/ou várias outras.

Deve-se enfatizar que é importante reiterar novamente, que este tipo de educação não-formal, não pode e não deve ser compreendida, em hipótese alguma, como algum tipo de proposta contra ou de alternativa à educação formal, escolar, considera-se que a mesma é um complemento importante para o aprendizado, em sala de aula. Essas mesmas práticas educativas não-formais, são complementares às práticas escolares, ou seja, não visa concorrer com esta, mas sim, desenvolver práticas que favoreçam o desenvolvimento crítico e participativo do cidadão na sociedade.

A educação não-formal, principalmente as extra-classes, se caracterizam pela intencionalidade de ensinar e deve ser uma prática desenvolvida por profissionais capacitados, portanto é uma ação estruturada, desenvolvida por indivíduos que compreendem a necessidade de trabalhar os saberes, que estão além dos bancos escolares, que visam então, atender as demandas de seus bairros ou comunidades. Isto favorece ao aluno, o desenvolvimento crítico, politizado, no intuito que este saiba conviver em sociedade, ou seja, saiba ser ético, coerente e compreender seus direitos e deveres.

Segundo Gohn (1999) a educação não-formal sempre foi considerado um campo de menor importância no Brasil e enfatiza que, quando são elaborados projetos de intervenção nessa linha, objetiva-se, em última instância, apenas certo tipo de enquadramento social dos jovens. 
Esse aspecto acaba por contribuir para que a educação não-formal seja ainda mais desconhecida e desvalorizada (GOHN, 1999).

A fim de que o trabalho em espaços não-formais seja desenvolvido, alguns conhecimentos do pedagogo devem ser considerados, uma vez que o trabalho exige algumas especificidades.

Silva e Perrude (2013, p. 54), dizem que em relação à formação e atuação, alguns princípios devem ser observados tais como: conhecimento da realidade da comunidade com a qual irá trabalhar; necessidade de propostas que contemplem objetivos pedagógicos explícitos com relação ao ato educativo; observação das necessidades da comunidade envolvida, numa proposta fundamentada e sempre sistematizada; clareza da ação. É necessário que se explicitem, num processo de conquista, também os pressupostos da ação do educador (compromisso social e político); reflitam em conjunto com a comunidade sobre a necessidade da luta para manter e conquistar novos direitos, desenvolvendo trabalhos que contemplem o tema cidadania; desenvolvam o trabalho junto à comunidade, com apoio de outros profissionais e instituições presentes e também líderes comunitários; utilizem de metodologias de pesquisa adequada e que visem transformações sociais; identificar-se com a questão e a comunidade com a qual irá trabalhar.

Em nossa perspectiva, estes seriam, então, alguns dos princípios orientadores, os quais devem perpassar a formação do pedagogo nestes tipos de abordagens, bem como podem se constituir como instrumental teórico, para o desenvolvimento do trabalho pedagógico nos espaços não-formais ou extra-classe.

Com isso, o pedagogo deve e pode assumir o seu papel, trabalhando tanto um tipo de educação quanto a outra (formal, e não-formal ou extra-classe), com um objetivo especificado e na busca pela formação humana de seus alunos.

O pedagogo é um profissional versátil que norteia a prática educativa e que ajuda no saber e no fazer das pessoas. Segundo Nascimento (2010, p. 62), a formação do pedagogo está diretamente relacionada com as transformações contemporâneas, enfocando o desenvolvimento humano, o trabalho em equipe, o aprofundamento teórico, estudando os processos de aprendizagem, as estratégias de ensino, dentre outros requisitos que conferem ao mesmo, sua especificidade. 
Embora o pedagogo se considere, atuando em novos e diferentes espaços, como trata este artigo, a preocupação com a formação do mesmo está dentro da própria equipe de profissionais, o que, nem sempre se é muito explorado nos cursos de formação inicial, ou então no caso, é feita de forma superficial (SILVA e PERRUDE, 2013, p. 55).

Busca-se para esse tipo de intervenção através das Universidades, por meio do Estágio Supervisionado, estar construindo e aprimorando o processo formação, assim dessa forma e nesta fase de aprendizado profissional, superar ou até, não correr o risco de cair, em uma redução teórico-conceitual da formação do pedagogo.

Para Silva e Perrude (2013, p. 55) a formação inicial é importante para o desenvolvimento do trabalho pedagógico, quando se trata do trabalho em espaço nãoformal, porém, do mesmo modo, é preciso uma formação que leve em conta as especificidades do trabalho, a criação de espaços de formação continuada como cursos, eventos e grupos de estudos, são, fundamentais para o fortalecimento, através da reflexão fundamentada, a atuação do pedagogo.

Contribui então, este profissional com questões de aprendizagem que influenciam no comportamento dos alunos, fazendo parte da organização, no sentido individual e coletivo. Portanto, vale ressaltar, que este profissional, tem suma importância nos espaços de educação não formal, assim como nas escolas. $O$ mesmo é considerado articulador e mediador de todo o processo pedagógico que acontece nesses espaços não-formais de ensino-aprendizagem.

\section{CONCLUSÃO}

A educação não-formal tratada neste artigo, é considerada de grande importância para a formação do cidadão, porém a mesma apresenta propósitos e objetivos diferentes, ou seja, trata-se de um trabalho extra-escolar, fora do ambiente formal de educação, ou seja a própria escola.

Pode-se afirmar que esse tipo de educação complementar é fundamental, pois atinge todas as classes $\mathrm{e}$ as vivências oferecidas nesses importantes espaços, promovem as construções coletivas através das interações entre os alunos, promovendo uma história individual e social, aos mesmos. 
Diante disso, pode-se afirmar que o professor norteador destas atividades, ou seja, o pedagogo, tem expressão fundamental nesse âmbito, sendo ele, o profissional orientador de todo esse processo pedagógico de aprendizagem.

Compreende-se que a educação não-formal não possui uma forma específica de ser e atuar, assim como a educação formal, pois, vale considerar o contexto na qual a instituição, em que o pedagogo está ou estaria, vinculado.

Contudo, podemos considerar que, a educação não-formal para muitos professores ainda é motivo de achar que é excesso de trabalho e poucos procuram utilizá-la e também ainda, muitos as desconhecem, pois as mesmas práticas estudadas, não podem acontecer de maneira descompromissada, principalmente para com os Direitos Humanos. As mesmas devem ser pensadas a partir de ações político-educativas, levando os sujeitos à promoção da educação, em um ambiente diferenciado.

Então, é preciso que, além de oferecer uma formação que permita uma visão crítica, que também haja espaço para que o pedagogo possa refletir acerca da sua prática pedagógica no seu cotidiano, a fim de que essa atuação, realmente se torne transformadora.

Outro aspecto é que o mesmo, não deve deixar acontecer um processo de escolarização de suas práticas, pois isso pode reduzir a qualidade do processo de educação não-formal extra-classe e então, não complementar com o seu papel formativo, além da atividade em que ele queira explorar.

Portanto, podemos concluir que ainda há muito que se investigar neste campo de atuação, que vem se consolidando na educação de nosso país, visto que é um setor em construção e se constitui num espaço importante de aperfeiçoamento profissional para professores em geral. Esse tipo de educação, não é estática, é uma atividade aberta que ainda está em construção, portanto, não tem uma identidade pronta e acabada.

Para complementar, é uma área bastante diversa, e esse aspecto é muito interessante, pois permite, além de contribuições de várias áreas, a composição de diferentes contextos culturais, tendo a diversidade como uma de suas características mais estudada.

Então, compete ao pedagogo ir além dos muros da escola e proporcionar uma vivência diferente ao público escolar e que auxilie seus alunos, no crescimento maior da educação, sendo esta, a formação do verdadeiro cidadão brasileiro. 


\section{REFERÊNCIAS}

FEltran, Regina Célia de Santis; FELTRAN FILHO, Antônio. Estudo do Meio. In: VEIGA, Ilma Passos Alencastro. Técnicas de Ensino: Por que não? Campinas: Papirus. Editora. 18 ed. 2007.

FREIRE, Paulo. Pedagogia da Autonomia: saberes necessários à prática educativa. São Paulo: Paz e Terra, 1996.

GERMANO, Marcelo Gomes. Uma nova ciência para um novo senso comum. Campina Grande: EDUEPB, 20II.

GOHN, Maria da Glória. Educação não formal e o educador social: atuação no desenvolvimento de projetos sociais. São Paulo, SP: Cortez, 2010.

O protagonismo da sociedade civil: movimentos sociais, ONGS e redes solidárias. 2 ed. São Paulo, SP: Cortez, 2008.

Educação não-formal e cultura política: impactos sobre o associativismo do terceiro setor. São Paulo: Cortez, 1999. (Coleção Questões da Nossa Época; v. 7I)

JACOBUCCI, Daniela Franco Carvalho. Contribuições dos espaços não-formais de educação para a formação da cultura científica. Em Extensão, Uberlândia, v.7, p.55-66, 2008.

LAKATOS, E. Maria; MARCONI, M. de Andrade. Fundamentos de metodologia científica: Técnicas de pesquisa. 7 ed. São Paulo: Atlas, 20II. 
NASCIMENTO, Aretha Soares. A atuação do pedagogo em espaços não escolares: desafios e possibilidades. Pedagogia em Ação, v. 2, n. I, p. I-Io3, fev./jun. 20Io. Disponível em: periodicos.pucminas.br. Acesso em 04/10/2021.

OLIVEIRA, Roni Ivan Rocha de; GASTAL, Maria Luíza de Araújo. Educação formal fora da sala de aula - olhares sobre o ensino de ciências utilizando espaços não-formais. (VII ENPEC - Encontro Nacional de Educação em Ciências, Florianópolis-SC) Nov/2009.

PAVIANI, Jayme. Ensinar: deixar aprender. Porto Alegre: EDIPUCRS, 2003. In: HEIDEGGER, M. 1951. El Ser Y el Tiempo. Mexico, Fondo de Cultura Econômica.

RANGEL, Mary. Métodos de Ensino para a Aprendizagem e a Dinamização das Aulas. Campinas: Papirus Editora. 2005.

REGO, Nelson. et al. Geografia: práticas pedagógicas para o ensino médio: volume 2. Porto Alegre: Penso, 20II.

ROCHA, Marcelo Augusto; FUSCALDO, Wladimir César. Educação não-formal por meio de reciclagem de resíduos sólidos: contribuições do Projeto Recriar. Londrina-PR Geografia, v. 19, n.3, 2010.

SILVA, Ana Lúcia Ferreira da; PERRUDE, Marleide Rodrigues. Atuação do pedagogo em espaços não-formais: algumas reflexões. Revista Eletrônica Pro-Docência/Uel. Edição №. 4, Vol. I, jul-dez. 2013. Disponível em: http://www.uel.br. Acesso em 04/ı/202I.

VEIGA, Ilma Passos Alencastro. A prática pedagógica do professor de Didática. 2 ed. Campinas, Papirus, 1992.

XAVIER, Odiva Silva; FERNANDES, Rosana César de Arruda. A Aula em Espaços Não-Convencionais. In: VEIGA, Ilma Passos Alencastro. Aula: Gênese, Dimensões, Princípios e Práticas. Campinas: Papirus Editora. 2008. 